\title{
Polysaccharides from Chrysanthemum morifolium Ramat ameliorate colitis rats by modulating the intestinal microbiota community
}

\author{
Jin-Hua Tao${ }^{1}$, Jin-Ao Duan ${ }^{2}$, Shu Jiang ${ }^{2}$, Nan-Nan Feng ${ }^{1}$, Wen-Qian Qiu ${ }^{1}$ and Yong \\ Ling ${ }^{1}$ \\ ${ }^{1}$ School of Pharmacy, Nantong University, Nantong 226001, PR China \\ ${ }^{2}$ Jiangsu Collaborative Innovation Center of Chinese Medicinal Resources Industrialization, Nanjing University of Chinese \\ Medicine, Nanjing 210023, PR China \\ Correspondence to: Jin-Hua Tao, email: taojinhua2000@163.com \\ Jin-Ao Duan, email: dja170626@163.com
}

Keywords: chrysanthemum polysaccharides, ulcerative colitis, 16 S rRNA, microbial diversity, short chain fatty acids

Received: April 13, $2017 \quad$ Accepted: July 26, $2017 \quad$ Published: August 24, 2017

Copyright: Tao et al. This is an open-access article distributed under the terms of the Creative Commons Attribution License 3.0 (CC BY 3.0), which permits unrestricted use, distribution, and reproduction in any medium, provided the original author and source are credited.

\section{ABSTRACT}

The gut microflora dysbiosis has been closely related with the inflammatory bowel disease (IBD). In this study, the effect of polysaccharides from Chrysanthemum morifolium Ramat on the gut microbiota was evaluated by ulcerative colitis (UC) rat model. Physiological and pathological analyses suggested that Chrysanthemum polysaccharides possessed notably protective effects on UC in vivo. Based on the Illumina MiSeq platform, 16S rRNA sequencing of the rat colonic contents indicated that the intestinal flora structure remarkably changed in the model rats and the tendency was alleviated to a certain degree by treatment with different dosages of Chrysanthemum polysaccharides. In normal groups, there were more Firmicutes than Bacteroidetes, but this change lost at the pathological state. Following Chrysanthemum polysaccharides, rising Firmicutes/Bacteroidetes ratio was validated. Besides the microbial diversity and the community richness of the UC rats were improved by Chrysanthemum polysaccharides, the composition of intestinal microflora in the model group were also restored after oral administration of Chrysanthemum polysaccharides. The abundance of opportunistic pathogens was decreased (Escherichia, Enterococcus and Prevotella), while the levels of protective bacteria such as Butyricicoccus and Clostridium (butyrate-producing bacteria), Lactobacillus and Bifidobacterium (probiotics), Lachnospiraceae and Rikenellaceae elevated in various degrees. Correlation analysis between intestinal flora and biochemical factors suggested that the relative abundance of protective bacteria was positively correlated with the levels of anti-inflammatory cytokines such as IL-4, IL-10 and IL-11, while aggressive bacteria were positively correlated with proinflammatory cytokine such as IL-23、IL-6、 IF-17、TNF- $\alpha$ IL-1 $\beta$ and IFN- $\gamma$. The above results showed that the intestinal flora were closely related to the secretion and expression of cytokines in the body, and they interacted with each other to regulate immune function. Thus, Chrysanthemum polysaccharides could ameliorate ulcerative colitis by fostering beneficial intestinal flora growth, modulating the balance of intestinal microecology and restoring the immune system. 


\section{INTRODUCTION}

Inflammatory bowel disease (IBD) encompasses two clinical forms such as ulcerative colitis (UC) and Crohn's disease (CD), which possesses some symptoms such as weight loss, severe diarrhea and abdominal pain, seriously impairing the quality of life $[1,2]$. To date, the pathogenesis of IBD remains unclear, though several factors have been associated with disease development including immune dysregulation, genetics, risk alleles, barrier dysfunction, environmental exposures and, more recently, compositional changes in the communities of bacteria that inhabit the gut [3-5]. The intestinal microflora dysbiosis is closely related to the gastrointestinal disease IBD [6]. The intestinal microflora, approximately 100 trillion microorganisms, is a large bacterial community that colonizes in the intestine, with powerfully metabolic activities for various enzymes and other functions such as intestinal epithelial cell proliferation/differentiation, intestinal development and barrier function that affect the physiology and pathology of the host's mucosal immune system [7-9]. Many researches have overwhelmingly verified the roles of bacteria in IBD. Chronic intestinal inflammation in transgenic and gene knock-out rats occurs under standard laboratory conditions, but not in a germ-free environment $[10,11]$.

Nowadays numerous researches have focused on profiling the microbial diversities in IBD and their differences with healthy individuals, which show that bacterial diversity, stability and cluster in IBD have been notably reduced. Based on direct sequencing of variable bands and verification by real time PCR, the intestinal bacteria such as Bacteroides, Eubacterium, and Lactobacillus were reduced in IBD [12]. Using metagenomic approach, Manichanh et al detected a reduced complexity of the bacterial phylum Firmicutes as a signature of the faecal microbiota in patients with IBD [13]. Bacteroidetes and Proteobacteria significantly increased in CD patients, while Clostridia reduced [14]. Firmicutes decreased in IBD along with increase of Bacteroidetes [2]. Some of the recent studies have also indicated the crucial role of Proteobacteria in the pathogenesis of ulcerative colitis $[15,16]$. Additionally, intestinal bacteria help supply host nutrition by producing short chain fatty acids (SCFAs) and vitamins, and play crucial roles in the maintenance of human health by preventing pathogen colonization and by shaping and maintaining normal mucosal immunity. SCFAs have established anti-inflammatory effects in a variety of animal colitis models [17].

Chrysanthemum, the dry capitulum of Chrysanthemum morifolium Ramat, has been clinically used to effectively cure some infectious and inflammatory diseases such as influenza, colitis, stomatitis for thousands of years in Korea and China. Additionally, it has been also applied to treat cancer, sores, vertigo and hypertension [18-21]. Our previous studies have demonstrated that the polysaccharides from Chrysanthemum morifolium Ramat possessed remarkably protective effects on DSS induced colitis by increasing SCFAs production [21].
However, the mechanisms on the colonic fermentation were deficiency and also limited data exist on the impact of Chrysanthemum polysaccharides on the gut microbiota.

Recently, based on the next generation sequencing Illumina Miseq of 16S rRNA gene libraries driven by high-throughput technologies, characterization of bacterial community diversity has been possible [22]. Assembly of short sequences into operational taxonomic units (OTUs) is an initially key process in analyzing metagenomic data [23]. In this study, the above method was used to evaluate dynamic changes of intestinal microflora in 2, 4, 6-trinitrobenzene sulfonic acid (TNBS) induced colitis after oral administration of polysaccharides from Chrysanthemum morifolium Ramat. Meanwhile, the correlation analysis between intestinal flora and colitisrelated biochemical factors was carried out to explore the possible mechanism of chrysanthemum polysaccharides to ameliorate TNBS-induced colitis. The Supplementary Figure 1 showed the experimental strategy.

\section{RESULTS}

\section{Amelioration of Chrysanthemum polysaccharides on TNBS-induced colitis}

In this study, intra-colonic instillation of TNBSinduced colitis rat model was established and successfully applied to evaluate the amelioration of Chrysanthemum polysaccharides. From the fourth day of rectal administration of TNBS, rats showed increasingly severe symptoms such as serious diarrhea, obvious rectal bleeding and notable body weight loss. Compared to the normal group (Figure 1A), TNBS-induced colitis rats (M) remarkably lost weight throughout the trial period $(\mathrm{p}<0.01)$, which was rescued by the Chrysanthemum polysaccharides treatment (HP 200 $\mathrm{mg} / \mathrm{kg}$, MP $100 \mathrm{mg} / \mathrm{kg}$, LP $50 \mathrm{mg} / \mathrm{kg}$ ). Disease activity index (DAI) was prominently higher in the model group than that in the normal group $(\mathrm{p}<0.01)$. Comparison with the model group, treatments with low and middle doses of Chrysanthemum polysaccharides and SASP notably reduced DAI $(\mathrm{p}<0.01)$. However, no remarkable differences were observed in HP groups (Figure 1B). Shortened colon length is an important physiological index of colitis. TNBS treated rats showed substantial reduction in colon length compared to the normal group $(\mathrm{p}<0.001)$. Chrysanthemum polysaccharides at $50 \mathrm{mg} / \mathrm{kg}$ alleviated the situation of colon shortening (Figure 1C) $(\mathrm{p}<0.05)$. The histopathological characteristics of colon tissues from each group were evaluated by H\&E staining. The results indicated that severe pathological changes such as mucosal lesion, necrosis and infiltration of inflammatory cells including monocytes and neutrophils occurred in the colonic tissues of model rats, which were alleviated by Chrysanthemum polysaccharides treatment, especially the MP $(100 \mathrm{mg} / \mathrm{kg})$ and $\mathrm{LP}(50 \mathrm{mg} / \mathrm{kg})$ $(\mathrm{p}<0.01)$ (Figure 1D).

To further evaluate the association between the alleviation of TNBS-induced colitis and inflammatory 
factors/cytokines in colitis rats, the levels of these factors/cytokines in colon epithelial tissue samples were quantified. Compared with normal rats, the levels of many cytokines including IL-6, TNF- $\alpha$, IL-17, IL23 , IL-1 $\beta$ and IFN- $\gamma$ were increased, while IL-13, IL-10 and IL-4 were decreased in TNBS-induced colitis rats. However, the cytokine levels tended to be restored to the normal group after oral administration of Chrysanthemum polysaccharides (Figure 2).

\section{High-throughput 16S rRNA sequencing of the rat colonic contents}

In this study, 30 gut content samples were applied to evaluate the amelioration of Chrysanthemum polysaccharides on TNBS-induced colitis. A high throughput sequencing on the Illumina MiSeq platform was performed and the results showed a total of 1,086,952 reads, which passed all quality filters under $97 \%$ identity conditions to obtain a total of 10,653 species classification OTUs. Each sample was covered by an average of 36,231 reads (Table 1). The individual rarefaction curves and Shannon Wiener curves of samples were close to the saturation plateau (Supplementary Figure 2), revealing that high sampling coverage $(\sim 99 \%)$ was obtained in all samples.

The ACE and Chaol reflect the community richness of species within a single sample, while Shannon and Simpson indexes represent microbial diversity. In Table 1, the ACE, Chao1, Shannon and Simpson indexes in the TNBS group were much lower than those in the normal control group, which were dramatically risen by Chrysanthemum polysaccharides treatment $(\mathrm{p}<0.01)$. However, statistical differences in alpha diversity were not observed among the three dosage (HP $200 \mathrm{mg} / \mathrm{kg}$; MP 100 $\mathrm{mg} / \mathrm{kg}$; LP $50 \mathrm{mg} / \mathrm{kg}$ ) of Chrysanthemum polysaccharides $(\mathrm{P}>0.05)$.

\section{OTU network analyses of bacterial communities}

OTUs and different treatment groups of $(\mathrm{N}, \mathrm{M}, \mathrm{PP}$, HP, MP and LP) rats were labeled as nodes in bipartite network. OTUs were linked with the samples, and their sequences would be found in OTU-nodes [24]. The OTUs network-based analyses showed that samples from LP, MP and PP were more closely related to $\mathrm{N}$ compared to HP and M (Figure 3), which suggested that samples among LP, MP and PP possessed higher similarity than that among HP and M. The above analyses would provide supports for the hypothesis that different treatment factors were selective pressures on microbiota and play key roles in the protective effects on TNBS-induced colitis.

\section{Comparison of the gut bacterial community among different treatment groups}

In this study, notable differences in richness and diversity of intestinal microflora among the different treatment groups were observed. A phylogenetic tree was used to detect changes of intestinal microflora among
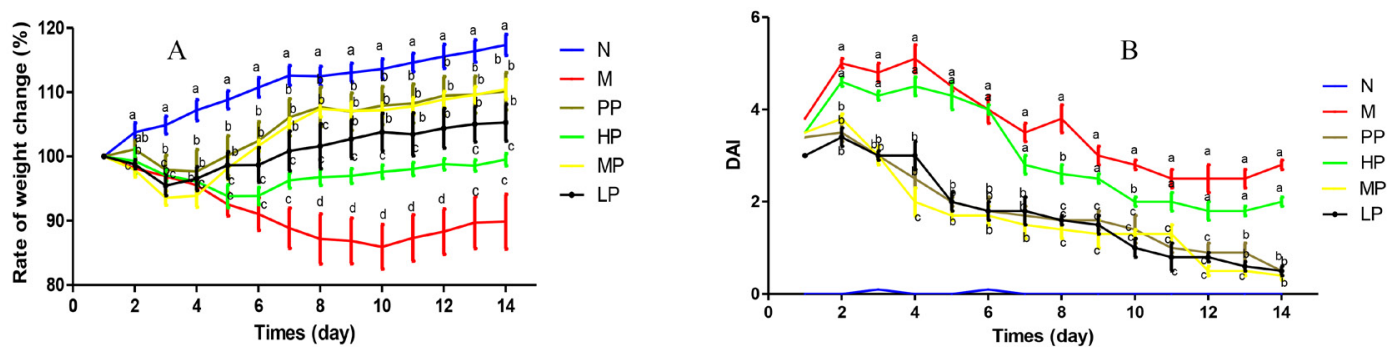

C

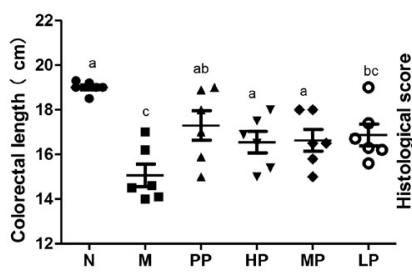

$\mathrm{D}$

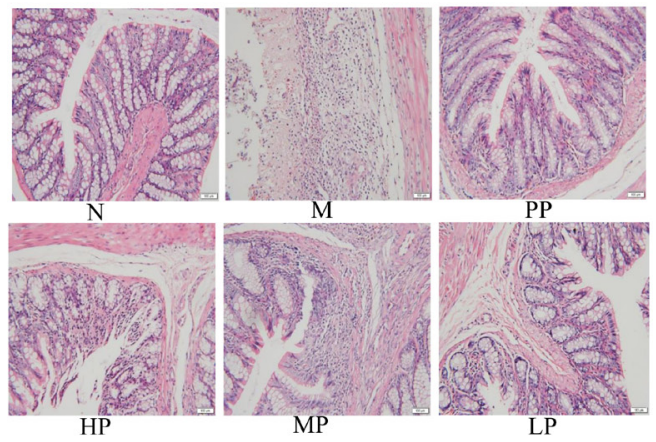

Figure 1: Chrysanthemum polysaccharides ameliorated TNBS-induced colitis in SD rats. (A) Change of body weight during the disease process. (B) DAI based on weight loss, hematochezia, and diarrhea. (C) Statistics of colon length of each group. (D) Histopathological changes of colons. Significant differences $(\mathrm{P}<0.05)$ between treatments were indicated by the letters a, $b$, or $c$. The results were presented as the mean $\pm \mathrm{SD} ; \mathrm{n}=6$ for each treatment. $\mathrm{N}$, normal group; M, TNBS-induced group; PP, SASP 0.5g/kg; HP, 200 $\mathrm{mg} / \mathrm{kg}$; MP, $100 \mathrm{mg} / \mathrm{kg} ; \mathrm{LP}, 50 \mathrm{mg} / \mathrm{kg}$. 
different treatment groups (Supplementary Figure 3). The greatest variations in intestinal microflora were found at the treatment of low dosage of Chrysanthemum polysaccharides (LP, $50 \mathrm{mg} / \mathrm{kg}$ ), which approached the normal group. Minimal inter-rat variation was detected in other treatment groups except for a special one. Bacterial communities were also clustered by using two dimensional of PCA and PCoA of unweighted unifrac distance matrices. As was shown in Figure 4, there was notable separation between model and normal rats. Model rats treated with middle and low dosage of Chrysanthemum polysaccharides respectively (MP, $100 \mathrm{mg} / \mathrm{kg}$; LP, 50 $\mathrm{mg} / \mathrm{kg}$ ) had higher similarities in bacterial members with normal rats through clustering closely on the two dimensional PCA and PCoA plot. The results revealed that Chrysanthemum polysaccharides had amelioration effect on TNBS-induced colitis.

Linear discriminant analysis (LDA) linked with effect size measurements was used to detect major bacteria in the different treatment groups. The major bacteria were multifarious in the $\mathrm{N}, \mathrm{M}, \mathrm{PP}$, HP, MP and LP treatment groups (Supplementary Figure 4). Ruminococcaceae, Prevotellaceae, Prevotella 9, Ruminococcaceae UCG_005, Blautia, Clostridiumsensustricto1, Clostridiaceae1,
Faecalitalea, Ruminococcus1, Selenomonadles, Phascolarctobacterium, Acidaminococcaceae and Negativicutes were the core microbes observed in the TNBS-induced colitis (M), while Fiemicutes, Clostridiales, Clostridia, Bacilli, Lactobacillales, Lactobacillaceae, Lactobacillus, Romboutsia and Peptostreptococcaceae were the core microbes in the normal group $(\mathrm{N})$. The results were accordant with the previous report that Clostridiaceae, Prevotellaceae and Ruminococcaceae were observed to be at higher levels in the individuals suffering from chronic inflammatory bowel disease [16]. In the Chrysanthemum polysaccharides treatment groups, Bacteroidetes, Bacteroidales, Bacteroidia, Bacteroidaceae, Bacteroides and Prevotellaceae UCG_001 were the core microbes in HP; Lachnospiraceae NK4A136, Ruminococcaceae UCG_014, Turicibacter and Enterorhabdus were the core microbes in MP; and Akkermansia, Verrucomicrobiae, Virrucomicrobia, Verrucomicrobiaceae, Verrucomicrobiales, Moryella, Erysipelatoclostridium, Enterococcaceae, Enterococcus, Coriobacteriaceae UCG_002, Ruminococcaceae UCG_009, Anaerostipes, Allobaculum, Catabacter, Bifidobacetriales, Bifidobacterium, Bifidobacteriaceae and Bacteroidetes were the core microbes in LP.
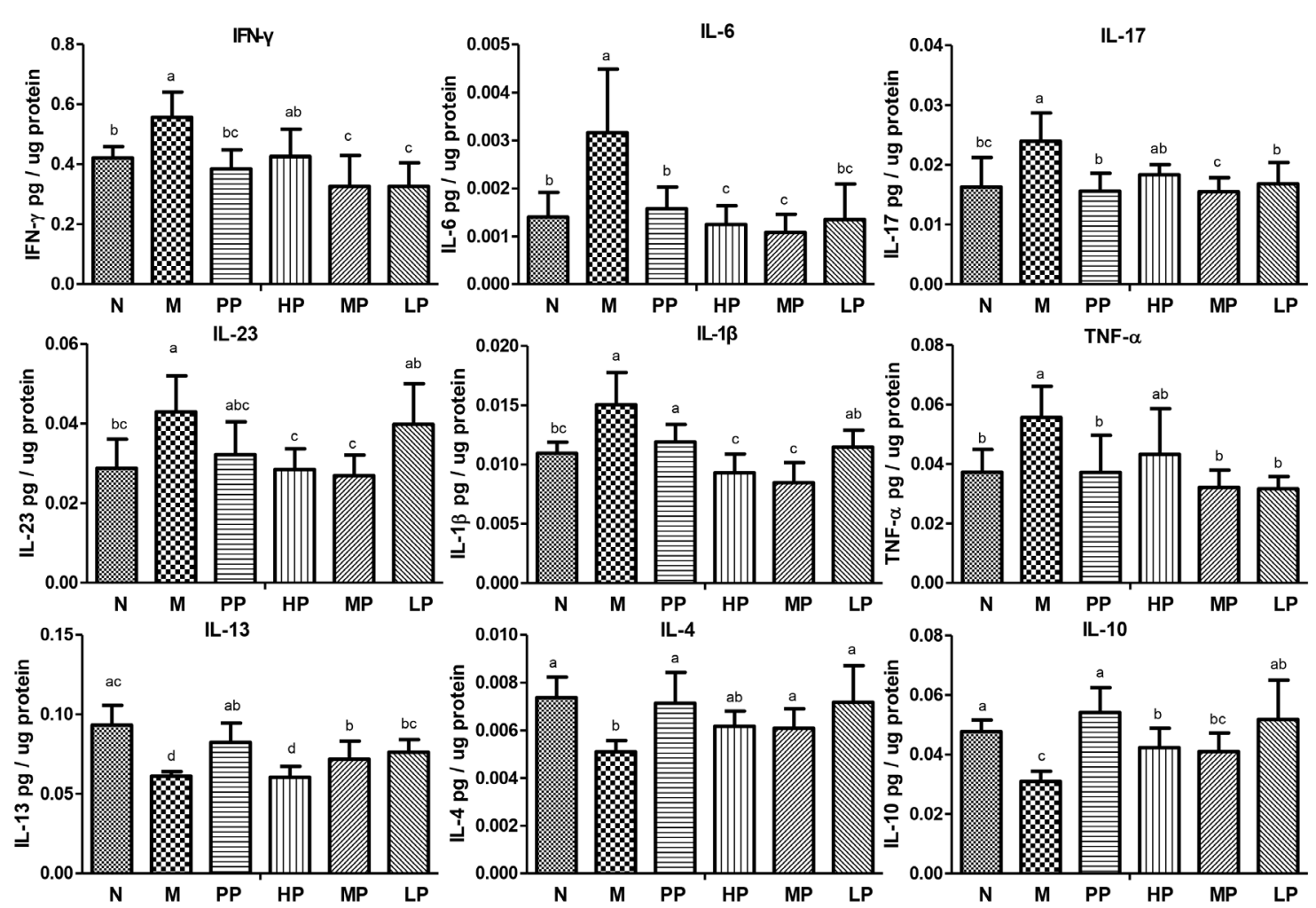

Figure 2: Chrysanthemum polysaccharides regulated cytokine profiles in colons mucosa of SD rats with TNBSinduced colitis. Cytokine levels in homogenated colonic proteins were assessed by ELISA. Significant differences $(\mathrm{P}<0.05)$ between treatments were indicated by the letters $a, b$, or $c$. The results were presented as the mean $\pm \mathrm{SD} ; \mathrm{n}=6$ for each treatment. N, normal group; M, TNBS-induced group; PP, SASP 0.5g/kg; HP, $200 \mathrm{mg} / \mathrm{kg}$; MP, $100 \mathrm{mg} / \mathrm{kg} ; \mathrm{LP}, 50 \mathrm{mg} / \mathrm{kg}$. 
Table 1: Richness and diversity estimation for colon contents bacterial populations based on alpha diversity analysis

\begin{tabular}{lcccc}
\hline \multirow{2}{*}{ group } & \multicolumn{3}{c}{$\mathbf{0 . 9 7}$} \\
\cline { 2 - 5 } & ACE & Chao1 & Shannon & Simpson \\
\hline $\mathrm{N}$ & $420.2 \pm 13.1$ & $421.2 \pm 12.8$ & $3.752 \pm 0.09$ & $0.0599 \pm 0.008$ \\
$\mathrm{M}$ & $367.4 \pm 36.8^{*}$ & $339.6 \pm 19.8^{*}$ & $3.104 \pm 0.29^{*}$ & $0.0634 \pm 0.015$ \\
$\mathrm{PP}$ & $359.6 \pm 41.4$ & $379.4 \pm 52.9$ & $3.684 \pm 0.22$ & $0.0707 \pm 0.024$ \\
$\mathrm{HP}$ & $404.2 \pm 40.9$ & $407.8 \pm 46.3$ & $3.658 \pm 0.53$ & $0.0902 \pm 0.055$ \\
MP & $417.0 \pm 39.0$ & $423.8 \pm 43.5^{\#}$ & $3.958 \pm 0.32^{\#}$ & $0.0530 \pm 0.011$ \\
LP & $453.2 \pm 23.2^{\#}$ & $458.8 \pm 27.3^{\#}$ & $3.940 \pm 0.32^{\#}$ & $0.0535 \pm 0.032$ \\
\hline
\end{tabular}

*, $\mathrm{P}<0.05, \mathrm{M} V S \mathrm{~N}$; \#\#, $\mathrm{P}<0.01, \#, \mathrm{P}<0.05$, polysaccharides group VS $\mathrm{M}$.

\section{Screening of characteristic differential bacteria and intervention of Chrysanthemum polysaccharides}

To corroborate the correlation between intestinal microflora and the effects of Chrysanthemum polysaccharides treatment, the abundance of different bacteria in all samples was analyzed. Totally 11 different bacterial phyla were identified. Composition and proportion of major bacteria largely shifted within the different treatment groups. The majorities of the sequences were Bacteroidetes (23.47\%) and Firmicutes (70.88\%), while the rest belonged to Actinobacteria $(0.87 \%)$ and Proteobacteria $(3.61 \%)$. In the 6 treatment groups, bacterial structures were similar, but composition proportion of different bacteria was quite different from each other. The same was true at the genus level
(Figure 5A). Compositional comparisons revealed inconsistent results but have generally identified decrease of the Firmicutes phylum in IBD [2]. The ratio Firmicutes/Bacteroidetes was changed between the normal group and TNBS group $(22.71 \pm 2.82$ in $\mathrm{N} v s$ $2.73 \pm 1.33$ in $\mathrm{M}, \mathrm{P}<0.001)$. In the normal group, there were much more Firmicutes than Bacteroidetes, but the difference lost at pathological state (Figure 5A). Following Chrysanthemum polysaccharides, rising Firmicutes/Bacteroidetes ratio was validated in the MP $(8.11 \pm 2.71)$ and LP $(4.19 \pm 1.30)$ groups, especially in the MP groups $(\mathrm{P}<0.01)$. Meanwhile, as were shown in Figure $5 \mathrm{~B}$ and $5 \mathrm{C}$, the relative abundance of twelve different flora, seven protective and five aggressive bacteria, in different treatment groups were addressed. For example, the facultative bacteria such as Lactobacillus and Lactobacillaceae were enriched in the normal group

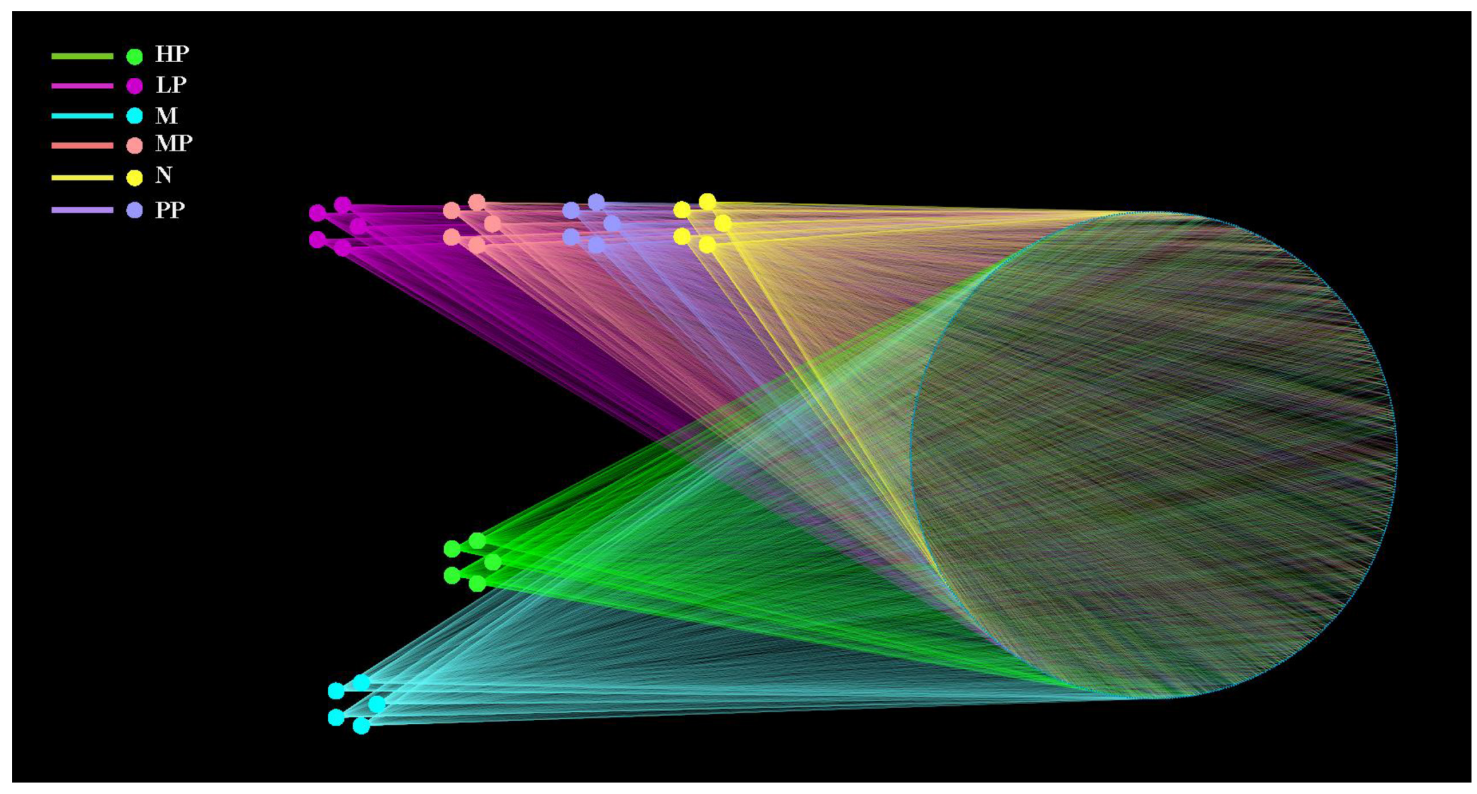

Figure 3: OTU network. OTU network analysis of bacterial communities from different treatment groups (N, M, PP, HP, MP, LP) for the V3-V4 16S rRNA region. 
(20.51\%), MP (19.38\%) and LP (14.38\%) respectively, while significantly decreased in TNBS-induced colitis (M) (6.24\% vs $20.51 \%, \mathrm{P}<0.01)$. What's more, Lactobacillus has been reported to own immunoregulatory properties [25]. After treatment of Chrysanthemum polysaccharides, the abundance of Lachnospiraceae $31.57 \%$ in MP vs $11.94 \%$ in $\mathrm{M}, \mathrm{P}<0.001)$ and Rikenellaceae $(0.026 \%$ in HP vs $0.004 \%$ in $\mathrm{M}, \mathrm{P}<0.001 ; 0.014 \%$ in MP $v s 0.004 \%$ in $\mathrm{M}, \mathrm{P}<0.01 ; 0.029 \%$ in LP vs $0.004 \%$ in $\mathrm{M}, \mathrm{P}<0.001$ ) significantly increased, while the abundance of prevotella decreased $(5.87 \%$ in $\mathrm{HP}$ vs $12.14 \%$ in $\mathrm{M}, \mathrm{P}<0.05 ; 1.86 \%$ in MP vs $12.14 \%$ in $\mathrm{M}, \mathrm{P}<0.001 ; 1.46 \%$ in $\mathrm{LP}$ vs $12.14 \%$ in $\mathrm{M}, \mathrm{P}<0.001$ ).

The commensal gut microbiota are very beneficial to the host, including maintenance of immune homeostasis [26], regulation of intestinal development, and enhancement of metabolic capabilities [27]. SCFAs, which are yielded majorly by bacterial metabolism, are important energy sources of colonic epithelial cells and can enhance the integrity of epithelial barrier and activate the gastrointestinal immune response, especially the butyrate [28-30]. The increase of butyrate-producing bacteria (e.g. Butyricicoccus, $0.37 \%$ in LP vs $0.20 \%$ in $\mathrm{M}, \mathrm{P}<0.01$; Clostridium, $0.95 \%$ in LP vs $0.59 \%$ in $\mathrm{M}, \mathrm{P}<0.01$ ) after oral administration of Chrysanthemum polysaccharides suggested that Chrysanthemum polysaccharides (LP, $50 \mathrm{mg} / \mathrm{kg}$ ) had the ability to ameliorate TNBS-induced colitis by modulating the intestinal microbiota community (Supplementary Figure 4). Consistent with previous studies [31], the Enterococcus significantly increased in the TNBS-induced colitics group $(0.51 \%$ in $\mathrm{M} v s \quad 0.12 \%$ in $\mathrm{N}, \mathrm{P}<0.001$ ) which decreased by Chrysanthemum polysaccharides. The abundance of Bifidobacterium was significantly increased by low dosage of Chrysanthemum polysaccharides $(0.086 \%$ in LP $v s 0.0 .06 \%$ in $\mathrm{M}, \mathrm{P}<0.01)$. Various Bifidobacterium strains (breve, catenulatum, longum and infantis) resulted in amelioration of intestinal inflammation in DSS-induced colitis in mice [32, 33].

Multivariate direct gradients (CCA) were used to analyze the relationship between inflammatory factors/ cytokines in colon epithelial tissue samples and intestinal flora. (Figure 6A and 6B). The results demonstrated that at phylum level, Bacteroidetes, Proteobacteria and Elusimicrobia (especially Bacteroidetes) were positively correlated with IL-23, TNF- $\alpha$, IL- $1 \beta$, IL-6, IF-17 and IFN- $\gamma$, which could promote the occurrence of inflammatory diseases. However, Cyanobacteria, Firmicutes, Actinobacteria and Sacchribacteria (especially Firmicutes) were positively correlated with IL-10, IL-13 and IL-4, which had the inhibition of inflammatory diseases. Obviously, both the MP and LP groups had positive effects on Firmicutes. At genus level, there was a significant positive correlation between protective bacteria such as Butyricicoccus, Clostridium, Lachnospiraceae, Rikenellaceae, Lactobacillus and Bifidobacterium and anti-inflammatory cytokine such as IL-4、IL-10、 IL-11, while aggressive bacteria such as Prevotella, Ruminococcus, Bacteroides, EscherichiaShigella, akkermansia, Turicibacter were positively correlated with proinflammatory cytokine such as IL-23 、 TNF- $\alpha$, IL-1 $\beta$ 、IL-6、IF-17 and IFN- $\gamma$.

The above results showed that the intestinal flora were closely related to the secretion and expression of cytokines in the body, and they interacted with each other to regulate immune function. Chrysanthemum polysaccharides could ameliorate TNBS-induced colitis by fostering beneficial intestinal flora growth, modulating the balance of intestinal microecology and restoring the immune system.
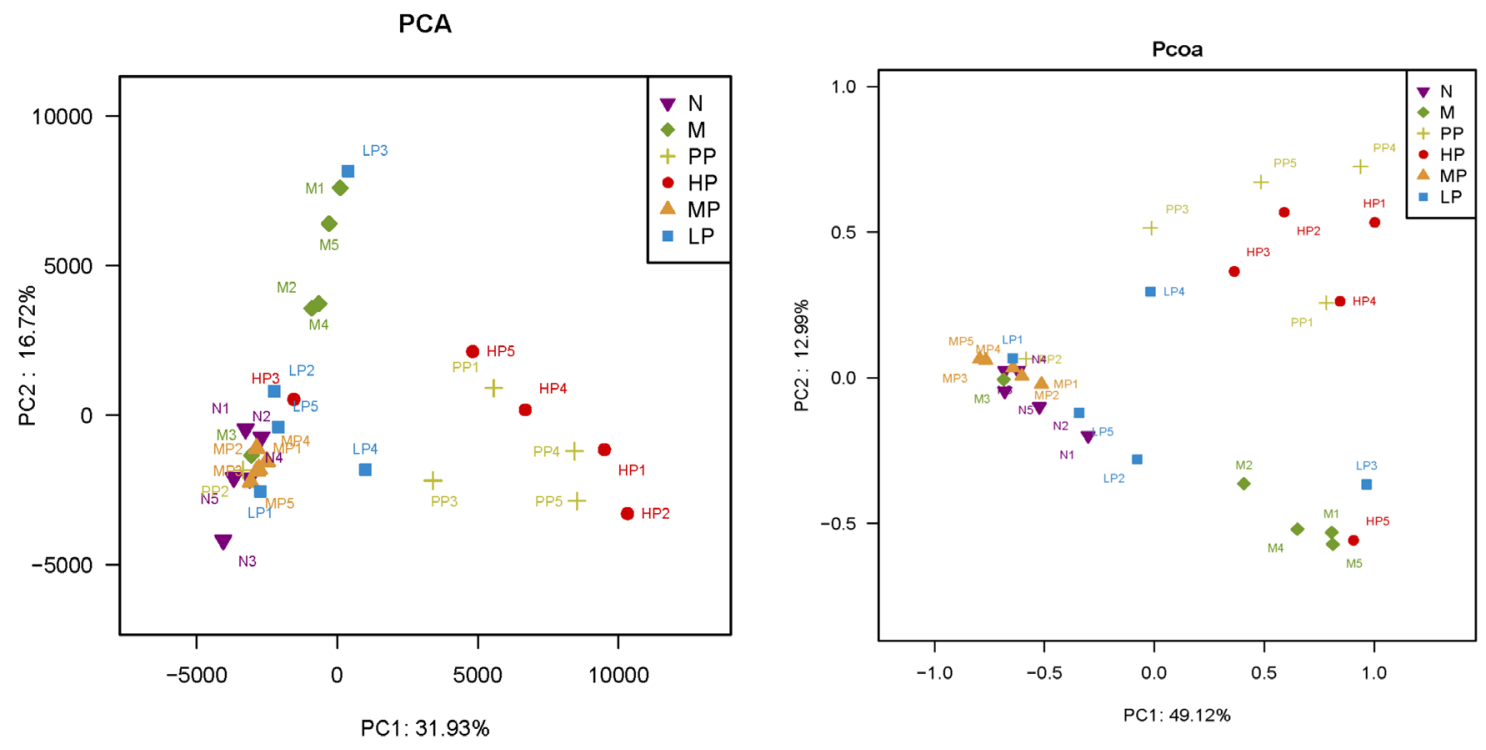

Figure 4: PCA (left) and PCoA (right) analysis of variation between the bacterial communities present in all biopsy samples. Each data point represents an individual sample. 

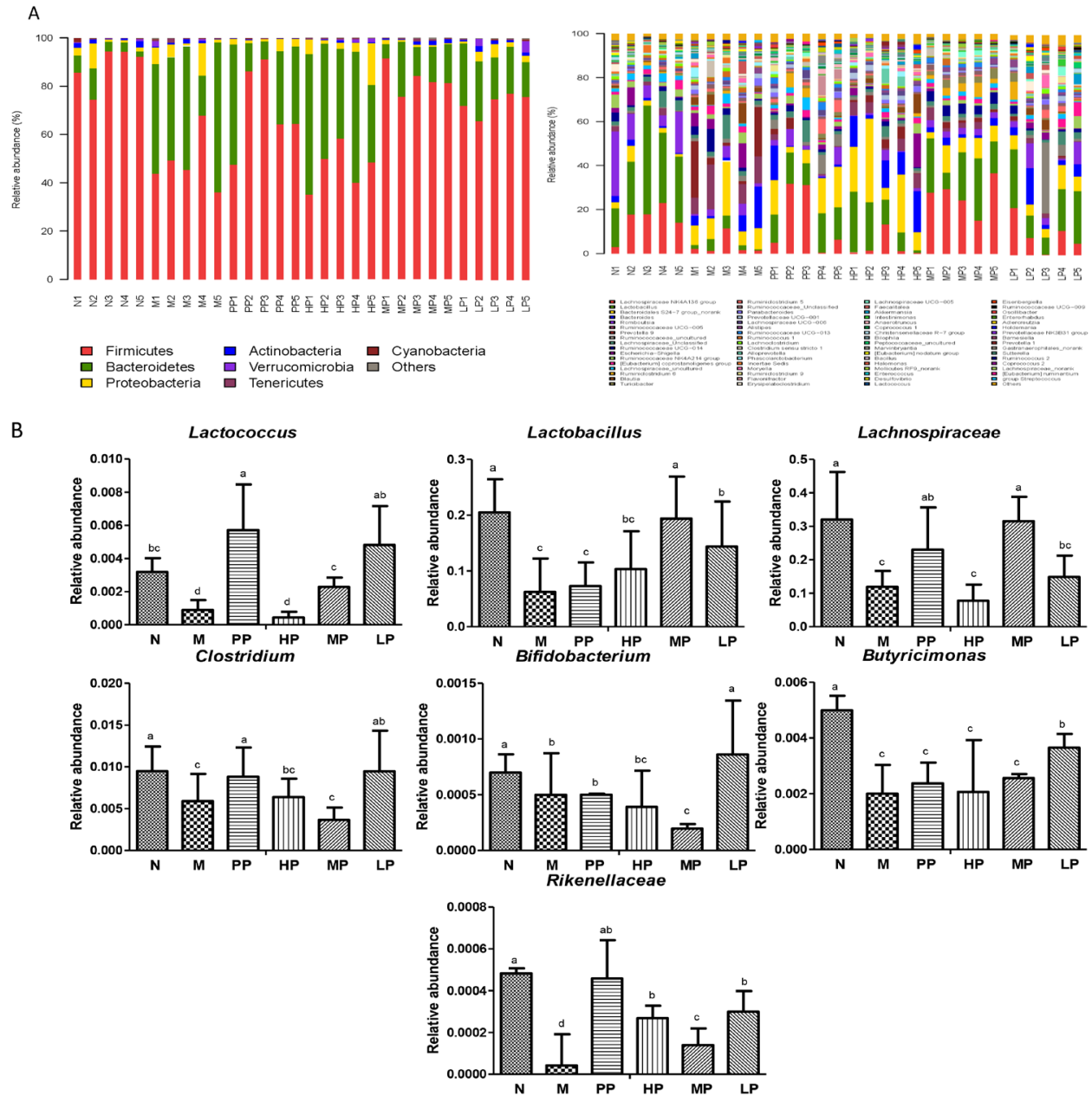

C
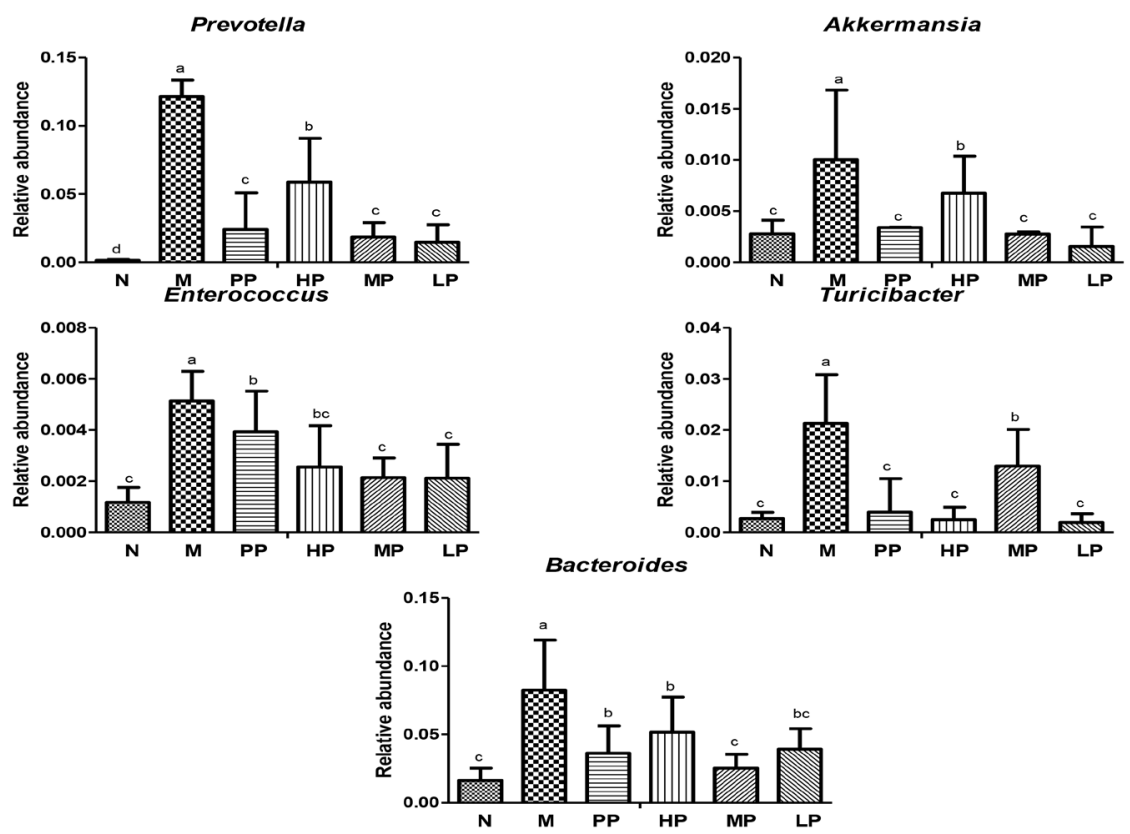

Figure 5: (A) Relative abundance of the main phyla and genes in the intestinal microbiota. Left: Phyla; Right: Genes. (B) Average relative abundance of seven protective bacteria in intestinal contents of different treatment groups. (C) Average relative abundance of five aggressive bacteria in intestinal contents of different treatment groups. Significant differences $(\mathrm{P}<0.05)$ between treatments were indicated by the letters $\mathrm{a}, \mathrm{b}$, or $\mathrm{c}$. The results were presented as the mean $\pm \mathrm{SD} ; \mathrm{n}=5$ for each treatment. N, normal group; M, TNBS-induced group; PP, SASP 0.5g/kg; HP, $200 \mathrm{mg} / \mathrm{kg}$; MP, $100 \mathrm{mg} / \mathrm{kg}$; LP, $50 \mathrm{mg} / \mathrm{kg}$. 


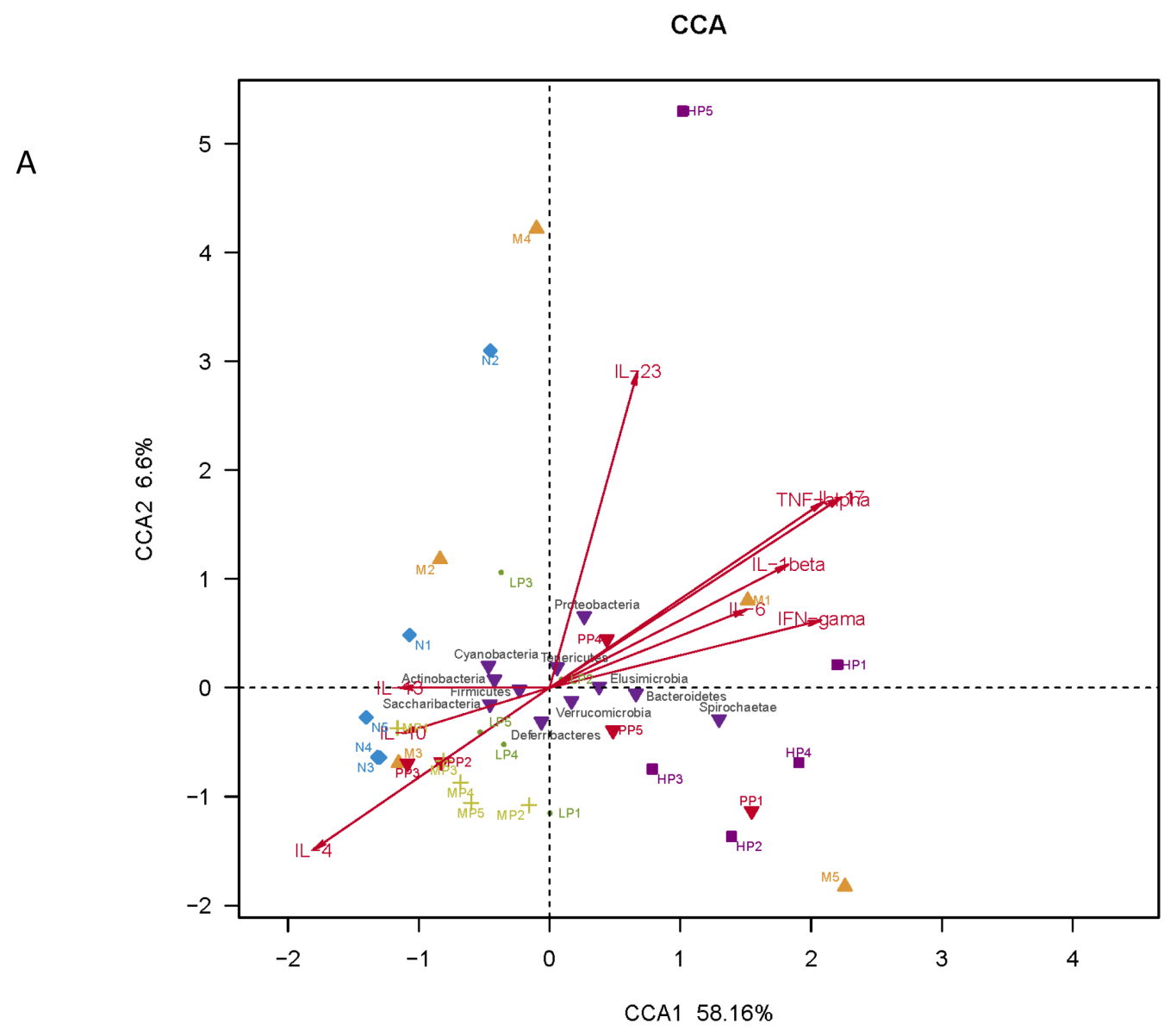

B

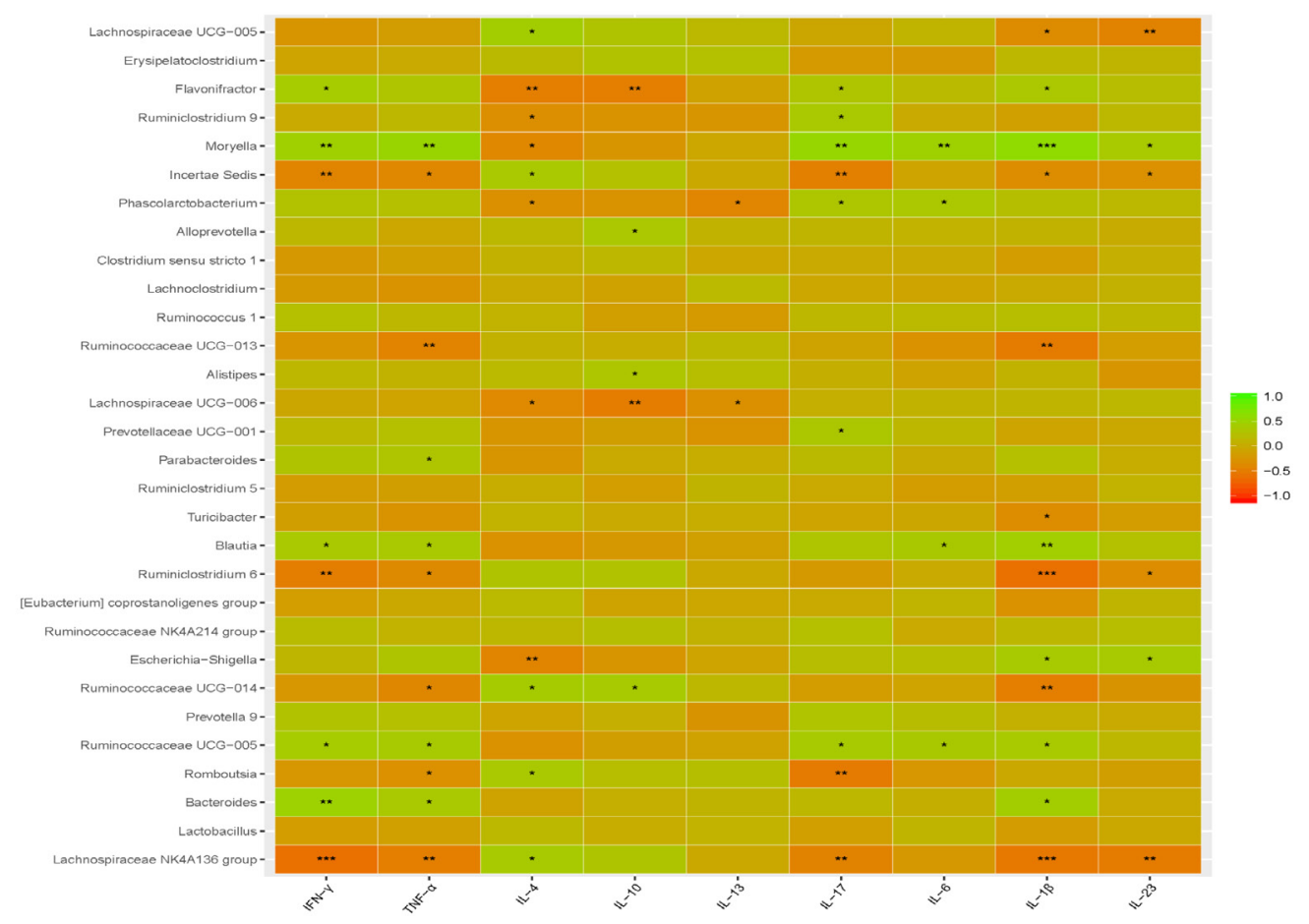

Figure 6: (A) The relationship between inflammatory factors/cytokines in colon epithelial tissue samples and intestinal flora based on CCA. (B) Heatmap correlation analysis of intestinal microflora and biochemical factors. 


\section{DISCUSSION}

The intestinal microflora is recorded as the highest cell density for any ecosystem, which has a profound and crucial influence on human health, and changes of intestinal microbiome may be associated with bowel diseases [27, 34]. 16S rDNA sequence-based methods showed that two kinds of bacteria, Bacteroidetes and Firmicutes, were the major gut microflora constituting over $90 \%$ of the known phylogenetic categories [35]. Colitis is mainly characterized by tissue damage and colon inflammation. The intestinal microflora is crucial for protection of intestinal mucosa and microbiota dysbiosis could lead to mucosal injury [36, 37]. It is reported that faecal bacteria from healthy donors are expected to have therapeutic effects on patients with IBD [38]. In this study, disequilibrium in the microbiota was observed in the TNBS-induces colitis rats. Intervention with Chrysanthemum polysaccharides alleviated the imbalances, reduced inflammation, and relieved symptoms of disease. Using 16S rRNA gene sequences analysis of content samples from the normal group, TNBS-induced colitis and sequential Chrysanthemum polysaccharides treatment groups, we observed that profiles of predominant bacteria changed persistently. The ratio Firmicutes/Bacteroidetes was decreased while the increase was validated after Chrysanthemum polysaccharides treatment, especially in the MP group.

The SCFAs not only provide large amounts of energy for colonocytes but also possess anti-inflammatory characteristics, including the capability to decrease cytokine response induced by lipopolysaccharide [29, 39]. Thus, the lack of Butyricicoccus and Clostridium could make some individuals susceptible to gut inflammation. Additionally, decreased relative abundance of potentially immunomodulatory mucosal-associated species such as Faecalibacterium prausnitzii, Clostridium leptum and Clostridium coccoides have been reported for UC patient samples [40, 41]. These organisms could produce SCFAs which have established anti-inflammatory effects in a variety of animal colitis models [17, 29]. So, loss of SCFAs-producing bacteria from IBD patients is believed to represent at least one mechanism by which microbial dysbiosis contributes to the heightened immune activation associated with the disease. However, in our studies, the abundance of Butyricicoccus and Clostridium notably increased after Chrysanthemum polysaccharides treatment compared with the model group. The result suggested that Chrysanthemum polysaccharides (LP, $50 \mathrm{mg} / \mathrm{kg}$ ) had the ability to ameliorate TNBS-induced colitis by modulating the intestinal microbiota community. Meanwhile, in our previous reports, compared with the DSS-treated colitis group, the SCFAs content in the different polysaccharidestreated group has remarkably increased which indicated that Chrysanthemum polysaccharides could contribute to bowel health by promoting SCFAs yield [21].
It is reported that enterotoxins can be produced by Bacteroides and Clostridia species characterized by proteolytic enzymes that heighten intestinal mucosal permeability and bacterial absorption [42]. In this study, more abundance of Bacteroides were observed in the model group than that in the normal group. However, the trend was reversed by Chrysanthemum polysaccharides (Figure 5C). Studies have revealed that virulence factors from adherent and invasive $E$ coli are required for its colonization of intestinal mucosa, breakthrough of the epithelial barrier, interaction with host macrophages, and induction of proinflammatory cytokine synthesis [43-45]. The abundances of two kinds of opportunistic pathogens, Escherichia and Enterococcus, enriched in the TNBS group. However, the notable decrease of Enterococcus was observed in Chrysanthemum polysaccharides-treated groups, which could be correlative to the anti-inflammatory activities of Chrysanthemum polysaccharides relieving symptoms of disease by reducing some opportunistic pathogens. It was reported that, the strain Lactobacillus subspecies could reduce mucosal permeability, prevent colitis onset, and alleviate inflammatory reaction in IL10-/- mice [37, 46]. Lactobacillus GG improved intestinal barrier function by inhibiting enterocyte apoptosis, and prevented colitis recurrence [47-49]. Previous studies have demonstrated that Prevotella was more abundant in IBD patients than in non-inflamed individuals. Consistent with the reports, we confirmed that the abundance of Prevotella increased heavily in the TNBS-induced colitics group, which decreased following Chrysanthemum polysaccharides treatment [2]. It indicated that the Lachnospiraceae could help maintain gastrointestinal tract health and be a powerful tool to evaluate intestinal health [50]. Alkadhi et al. found that Rikenellaceae abundance reduced in Muc2 deficient mice compared to healthy ones [51]. Thus, we have reason to believe that Chrysanthemum polysaccharides could prevent inflammatory disease by the changes of the gut microbial community.

It is believed that CD4 $+\mathrm{T}$ cells, which are an important part of the immune system, can not be neglected in the pathogenesis of IBD. The imbalance of maintenance-regulated factors/cytokines expression in Th1, Th2, Th17, Treg cells may be one of the main mechanisms of disease $[52,53]$. In this study, following Chrysanthemum polysaccharides treatment, the levels of cytokines IFN- $\gamma$, IL- $1 \beta$ and TNF- $\alpha$ which secreted by Th1 were decreased significantly, so were IL-6, IL-17 and IL23 which secreted by Th17, while IL-13, IL-10 and IL-4 which secreted by Th2 were increased. Unbalanced Th1 / Th2, Th17/Treg was alleviated.

Correlation analysis between intestinal flora and biochemical factors indicated that there was a significantly positive correlation between protective bacteria such as Butyricicoccus, Clostridium, Lachnospiraceae, Rikenellaceae, Lactobacillus and Bifidobacterium and anti-inflammatory cytokines such as IL-4、IL-10 、IL- 
11, while aggressive bacteria such as Prevotella, Ruminococcus, Bacteroides, Escherichia-Shigella, akkermansia, Turicibacter were positively correlated with proinflammatory cytokines such as IL-23、TNF$\alpha$ IL-1 $\beta$, IL-6、IF-17 and IFN- $\gamma$. The above results showed that the intestinal flora were closely related to the secretion and expression of cytokines in the body, and they interacted with each other to regulate immune function. Chrysanthemum polysaccharides foster beneficial intestinal flora growth, modulate the balance of intestinal microecology, restore the immune system, so as to ameliorate TNBS-induced colitis.

In conclusion, based on Illumina Miseq platform analysis, Chrysanthemum polysaccharides improved the microbial diversity and the community richness of the TNBS-induced rats, and the population composition and diversity of intestinal microflora in the TNBS group were restored after oral administration of Chrysanthemum polysaccharides. Opportunistic pathogens decreased (Enterococcus, Escherichia and prevotella), while the abundances of Bifidobacterium, Butyricicoccus, Clostridium, Lachnospiraceae, Lactobacillus and Rikenellaceae were elevated in various degrees. Thus, Chrysanthemum polysaccharides could ameliorate TNBSinduced colitis by modulating the intestinal microbiota community.

\section{MATERIALS AND METHODS}

\section{Animals}

Male Sprague-Dawley (SD) rats (body weight 220-250 g) were bought from the Vital River Laboratory Animal Technology Co., Ltd. (Beijing, China). The IACUC number is "SCXK2012-0001". The animal experiments were performed according to the Regulations of Experimental Animal Administration (State Committee of Science and Technology of the People's Republic of China). The rats were housed in the specific pathogenfree (SPF) animal center for drug safety evaluation and research at Nanjing University of Chinese Medicine with an air-conditioned animal quarter with $12 \mathrm{~h}$ light/12 h dark cycle at a temperature of $22 \pm 2{ }^{\circ} \mathrm{C}$ and a relative humidity of $50 \pm 10 \%$. All rats were acclimatized for 7 days before any experiments and were fed with standard chow and water ad libitum.

\section{Chemical regents}

TNBS was bought from MP Biomedical (Aurora, $\mathrm{OH}, \mathrm{USA}$ ). Sulfasalazine (SASP) was obtained from Yifeng Pharmacy in Nanjing, China. TNF- $\alpha$, IFN- $\gamma$, IL-17, IL-6, IL-1 $\beta$, IL-23, IL-13, IL-10 and IL-4 enzyme linked immunosorbent assay (ELISA) kits were obtained from Nanjing Jiancheng Bioengineering Institute Co., Ltd., Nanjing, China. The dried flowers of C. morifolium were purchased from Yang-ma town of She-yang county in Jiangsu province of China. Chrysanthemum polysaccharides were obtained according to our previous studies [21].

\section{Animal model of colitis}

Acute colitis rats were induced by rectal administration of TNBS mixed with a certain percentage of ethanol through a special catheter [54]. Briefly, rats were anaesthetized with $10 \%$ chloral hydrate, and subsequently administered with $3 \mathrm{~mL} / \mathrm{kg}$ of TNBS-ethanol solution (50 $\mathrm{mg} / \mathrm{mL}$ ) into the colon at $8-10 \mathrm{~cm}$ depth from the rectum using a soft polyethylene catheter. The rats were fastened in the trendelenburg position for one minute to avoid loss of TNBS solution via the rectum. While normal rats were rectally administered with normal saline at equivalent instead of TNBS [55].

\section{Experimental procedures}

24 hours (day 1) after induction of colitis, all the rats were randomly assigned to six groups, five rats were chosen in each group: Normal group $(\mathrm{N})$, receiving normal saline at equivalent and received intragastric administration (ig) saline during treatment; TNBS model group (M), receiving ethanol vehicle with TNBS (TNBS + saline); Sulfasalazine group (PP), receiving SASP $0.5 \mathrm{~g} / \mathrm{kg}$ (TNBS + SASP); Chrysanthemum polysaccharides (CP) high, middle and low dose treatment group (HP, MP, LP), receiving CP $200 \mathrm{mg} / \mathrm{kg}$ (TNBS + HP), $100 \mathrm{mg} / \mathrm{kg}$ (TNBS $+\mathrm{MP})$ and $50 \mathrm{mg} / \mathrm{kg}(\mathrm{TNBS}+\mathrm{LP})$, respectively. All above treatments from day 2 to day 15 . The rats were detected daily for colitis by clinical symptoms including body weight, gross rectal bleeding and stool consistency, which was assessed by DAI according to the method described by Cooper [56]. $24 \mathrm{~h}$ after the last treatment (day 16), all rats were sacrificed after ether deep anesthesia. The colons were cut off, dissected along the longitudinal mesentery, rinsed with isotonic saline and subsequently used to assess colonic mucosa damage. Additionally, colonic contents were obtained. All the biological samples were stored at $-80^{\circ} \mathrm{C}$.

\section{Bacterial DNA extraction and PCR amplification}

Microbial DNA was extracted from colonic contents with the E.Z.N.A. ${ }^{\circledR}$ Soil DNA Kit (Omega Bio-tek, Norcross, GA, U.S.). The V3-V4 regions of the bacterial $16 \mathrm{~S}$ rDNA were amplified by PCR $\left(95{ }^{\circ} \mathrm{C}\right.$ for $4 \mathrm{~min}$, followed by 25 cycles at $95{ }^{\circ} \mathrm{C}$ for $30 \mathrm{~s}, 55{ }^{\circ} \mathrm{C}$ for $30 \mathrm{~s}$, and $72{ }^{\circ} \mathrm{C}$ for $45 \mathrm{~s}$ and a final extension at $72{ }^{\circ} \mathrm{C}$ for $10 \mathrm{~min}$ ) using primers $341 \mathrm{~F}$ 5'-barcode- CCTAYGGGRBGCASCAG)-3' and 806R 5'- GGACTACNNGGGTATCTAAT -3'. PCR reactions were carried out in triplicate $20 \mu \mathrm{L}$ mixture including $5 \mu \mathrm{M}$ primer $(0.8 \mu \mathrm{L}), 2.5 \mathrm{mM}$ dNTPs $(2 \mu \mathrm{L})$, FastPfu 
polymerase $(0.4 \mu \mathrm{L})$, template DNA (10 ng) and $5 \times$ FastPfu buffer $(4 \mu \mathrm{L})$. Amplicons were extracted from $2 \%$ agarose gels and purified with the AxyPrep DNA Gel Extraction Kit (Axygen Biosciences, Union City, CA, U.S.) and quantified with QuantiFluor ${ }^{\mathrm{TM}}$-ST (Promega, U.S.).

\section{Illumina MiSeq sequencing}

Purified PCR products were quantified by Qubit ${ }^{\circledR} 3.0$ (Life Invitrogen) and every twenty-four amplicons were mixed equally. The pooled DNA products were applied to establish Illumina Pair-End library by Illumina's genomic DNA library preparation procedure. Then the amplicon library was paired-end sequenced $(2 \times 250)$ on an Illumina MiSeq platform (Shanghai BIOZERON Co., Ltd) according to the standard protocols.

\section{Cytokine assay}

Colonic tissue $(50 \mathrm{mg})$ was extracted with $500 \mathrm{uL}$ of guanidine $\mathrm{HCl}(5 \mathrm{M})$ and Tris- $\mathrm{HCl}$ (50 mM, pH 8.0) containing a protease inhibitor. Then, the extracts were centrifuged at $4{ }^{\circ} \mathrm{C}(13,000 \mathrm{~g} \times 10 \mathrm{~min})$, and subsequently the supernatant fractions were used to determine cytokines by ELISA kit (Nanjing Jiancheng Bioengineering Institute Co., Ltd. Nanjing, China) according to the manufacturer's instructions.

\section{Process of sequencing data}

Raw fastq files were demultiplexed and qualityfiltered with QIIME (version 1.17) $[57,58]$. OTUs $(97 \%$ similarity) were clustered with UPARSE version 7.1 http://drive5.com/uparse/) and chimeric sequences were authenticated and deleted by UCHIME. The genetic relationship of each $16 \mathrm{~S}$ rDNA sequence was evaluated by Ribosomal Database Project Classifier (http://rdp.cme. msu.edu/) based on the silva database $[59,60]$.

\section{Diversity analysis}

In the alpha diversity analysis which based on Mothur v.1.21.1 [61], community richness was estimated by the diversity indices including Chao 1 and ACE. Community evenness was assessed by the Simpson index and Shannon index. Estimators of population diversity, evenness and richness were calculated by OTUs (97\% similarity). The beta diversity analysis was performed using UniFracto compare the results of the principal coordinate analysis (PCoA) and principal component analysis (PCA) [62].

\section{Statistical analysis}

The experimental data were analyzed by GraphPad PrismV5 software. The results were expressed as mean \pm standard deviation $(\mathrm{X} \pm \mathrm{SD})$. The average numbers of groups were compared by one-way-ANOVA with Tukey's honestly significant difference (HSD) post hoc test. $\mathrm{p}<0.05$ was considered to be remarkably different [63].

\section{Abbreviations}

TNBS: 2, 4, 6-trinitrobenzene sulfonic acid; SASP: Sulfasalazine; N: Normal group; M: TNBS/ethanol model group; PP: TNBS/ethanol + SASP $(0.5 \mathrm{~g} / \mathrm{kg})$; HP: TNBS/ ethanol + high dose treatment group $(200 \mathrm{mg} / \mathrm{kg})$; MP: TNBS/ethanol + middle dose treatment group (100 mg/ $\mathrm{kg}$ ); LP: TNBS/ethanol + low dose treatment group (50 $\mathrm{mg} / \mathrm{kg}$ )

\section{ACKNOWLEDGMENTS}

This work was financially supported by Jiangsu Collaborative Innovation Center of Chinese Medicinal Resources Industrialization (No. ZDXM-1-10).

\section{CONFLICTS OF INTEREST}

The authors declare no conflicts of interest.

\section{REFERENCE}

1. Pizzi LT, Weston CM, Goldfarb NI, Moretti D, Cobb N, Howell JB, Infantolino A, Dimarino AJ, Cohen S. Impact of chronic conditions on quality of life in patients with inflammatory bowel disease. Inflamm Bowel Dis. 2006; $12: 47-52$.

2. Walker AW, Sanderson JD, Churcher C, Parkes GC, Hudspith BN, Rayment N, Brostoff J, Parkhill J, Dougan G, Petrovska L. High-throughput clone library analysis of the mucosa-associated microbiota reveals dysbiosis and differences between inflamed and non-inflamed regions of the intestine in inflammatory bowel disease. BMC Microbiol. 2011; 11:7-19.

3. Kucharzik T, Maaser C, Lugering A, Kagnoff M, Mayer L, Targan S, Domschke W. Recent understanding of IBD pathogenesis: implications for future therapies. Inflamm Bowel Dis. 2006; 12:1068-1082.

4. Packey CD, Sartor RB. Interplay of commensal and pathogenic bacteria, genetic mutations, and immunoregulatory defects in the pathogenesis of inflammatory bowel diseases. J Intern Med. 2008; 263:597-606.

5. Mar JS, Nagalingam NA, Song YL, Onizawa M, Lee JW, Lynch SV. Amelioration of DSS-induced murine colitis by VSL\#3 supplementation is primarily associated with changes in ileal microbiota composition. Gut Microbes. 2014; 5: 494-503.

6. Kostic AD, Xavier RJ, Gevers D. The microbiome in inflammatory bowel disease: current status and the future ahead. Gastroenterology. 2014; 146:1489-1499. 
7. Turnbaugh PJ, Ley RE, Hamady M, Fraser-Liggett CM, Knight R, Gordon JI. The human microbiome project. Nature. 2007; 449:804-810.

8. Hooper LV, Stappenbeck TS, Hong CV, Gordon JI. Angiogenins: a new class of microbicidal proteins involved in innate immunity. Nat Immunol. 2003; 4:269-273.

9. Qin J, Li R, Raes J, Raes J, Burgdorf KS, Manichanh C, Nielsen T, Pons N, Levenez F, Yamada T, Mende DR, $\mathrm{Li} \mathrm{J}, \mathrm{Xu} \mathrm{J}$, et al. A human gut microbial gene catalogue established by metagenomic sequencing. Nature. 2010; 464:59-65.

10. Sellon RK, Tonkonogy S, Schultz M, Dieleman LA, Grenther W, Balish E, Rennick DM, Sartor RB. Resident enteric bacteria are necessary for development of spontaneous colitis and immune system activation in interleukin-10-deficient mice. Infect Immun. 1998; 66: 5224-5231.

11. Kishi D, Takahashi I, Kai Y, Tamagawa H, Iijima H, Obunai $\mathrm{S}$, Nezu R, Ito T, Matsuda H, Kiyono H. Alteration of V beta usage and cytokine production of CD4+ TCR beta beta homodimer $\mathrm{T}$ cells by elimination of bacteroides vulgatus prevents colitis in TCR alpha-chain-deficient mice. J Immunol. 2000; 165:5891-5899.

12. Ott SJ, Musfeldt M, Wenderoth DF, Hampe J, Brant O, Fo"lsch UR, Timmis KN, Schreiber S. Reduction in diversity of the colonic mucosa associated bacterial microflora in patients with active inflammatory bowel disease. Gut. 2004; 53:685-693.

13. Manichanh C, Rigottier-Gois L, Bonnaud E, Gloux K, Pelletier E, Frangeul L, Nalin R, Jarrin C, Chardon P, Marteau P, Roca J, Dore J. Reduced diversity of faecal microbiota in Crohn's disease revealed by a metagenomic approach. Gut. 2006; 55:205-211.

14. Gophna U, Sommerfeld K, Gophna S, Doolittle WF, van Zanten SJ. Differences between tissue-associated intestinal microfloras of patients with Crohn's disease and ulcerative colitis. J Clin Microbiol. 2006; 44:4136-4141.

15. Garrett WS, Gallini CA, Yatsunenko T, Michaud M, DuBois A, Delaney ML, Punit S, Karlsson M, Bry L, Glickman JN, Gordon JI, Onderdonk AB, Glimcher LH. Enterobacteriaceae act in concert with the gut microbiota to induce spontaneous and maternally transmitted colitis. Cell Host Microbe. 2010; 8:292-300.

16. Walujkar SA, Dhotre DP, Marathe NP, Lawate PS, Bharadwaj RS, Shouche YS. Characterization of bacterial community shift in human Ulcerative Colitis patients revealed by illumina based 16S rRNA gene amplicon sequencing. Gut Pathog. 2014; 6:22-33.

17. Smith PM, Howitt MR, Panikov N, Michaud M, Gallini CA, Bohlooly YM, Glickman JN, Garrett WS. The microbial metabolites, short-chain fatty acids, regulate colonic Treg cell homeostasis. Science. 2013; 341:569-573.
18. Luyen BT, Tai BH, Thao NP, Cha JY, Lee HY, Lee YN, Kim YH. Anti-inflammatory components of Chrysanthemum indicum flowers. Bioorg Med Chem Lett. 2015; 25:266-269.

19. Zheng C, Dong Q, Du Z, Wang P, Ding K. Structural elucidation of apolysaccharide from Chrysanthemum morifolium flowers with anti-angiogenicactivity. Int J Biol Macromol. 2015; 79:674-680.

20. Kim C, Kim MC, Kim SM, Nam D, Choi SH, Kim SH, Ahn KS, Lee EH, Jung SH, Ahn SH. Chrysanthemum indicum L. extract induces apoptosis throughsuppression of constitutive STAT3 activation in human prostate cancer DU145cells. Phytother. Res. 2013; 27:30-38.

21. Tao JH, Duan JA, Jiang S, Guo JM, Qian YY, Qian DW. Simultaneous determination of six short-chain fatty acids in coloniccontents of colitis mice after oral administration of polysaccharidesfrom Chrysanthemum morifolium Ramat by gas chromatography withflame ionization detector. J Chromatogr B. 2016; 1029:88-94.

22. Mancuso FP, D'Hondt S, Willems A, Airoldi L, De Clerck O. Diversity and temporal dynamics of the epiphytic bacterial communities associated with the canopy-forming seaweed Cystoseira compressa (Esper) Gerloff and Nizamuddin. Front Microbiol. 2016; 7:476-487.

23. Wei ZG, Zhang SW. MtHc: a motif-based hierarchical method for clustering massive 16S rRNA sequences into OTUs. Mol BioSyst. 2015; 11:1907-1913.

24. DeSantis TZ, Dubosarskiy I, Murray SR, Andersen GL. Comprehensive aligned sequence construction for automated design of effective probes (CASCADE-P) using 16S rDNA. Bioinformatics. 2003; 19:1461-1468

25. Zeuthen LH, Christensen HR, Frokiaer H. Lactic acid bacteria inducing a weak interleukin-12 and tumor necrosis factor alpha response in human dendritic cells inhibit strongly stimulating lactic acid bacteria but act synergistically with gram-negative bacteria. Clin Vacc Immunol. 2006; 13:365-375.

26. Rakoff-Nahoum S, Paglino J, Eslami-Varzaneh F, Edberg S, Medzhitov R. Recognition of commensal microflora by tolllike receptors is required for intestinal homeostasis. Cell. 2004; 118:229-241.

27. Ley RE, Backhed F, Turnbaugh P, Lozupone CA, Knight RD, Gordon JI. Obesity alters gut microbial ecology. Proc Natl Acad Sci U S A. 2005; 102:11070-11075.

28. Mortensen PB, Clausen MR. Short-chain fatty acids in the human colon: relation to gastrointestinal health and disease. Scand J Gastroenterol. 1996; 31:132-148.

29. Segain JP, de la Bletiere DR, Bourreille A, Leray V, Gervois N, Rosales C. Butyrate inhibits inflammatory responses through NF kappa B inhibition: implications for Crohn's disease. Gut. 2000; 47:397-403.

30. Vinolo MA, Rodrigues HG, Hatanaka E, Sato FT, Sampaio SC, Curi R. Suppressive effect of short-chain fatty acids on production of proinflammatory mediators by neutrophils. J Nutr Biochem. 2011; 22:849-855. 
31. Neut C, Bulois P, Desreumaux P. Changes in the bacterial flora of the neoterminal ileum after ileocolonic resection for Crohn's disease. Am J Gastroenterol 2002; 97:939-46.

32. Osman N, Adawi D, Molin G, Ahrne S, Berggren A, Jeppsson B. Bifidobacterium infantis strains with and without a combination of oligofructose and inulin (OFI) attenuate inflammation in DSS-induced colitis in rats. BMC Gastroenterol. 2006; 6:31-41.

33. Setoyama H, Imaoka A, Ishikawa H, Umesaki Y. Prevention of gut inflammation by Bifidobacterium in dextran sulfatetreated gnotobiotic mice associated with Bacteroides strains isolated from ulcerative colitis patients. Microbes Infect. 2003; 5:115-122.

34. Qin JJ, Li RQ, Raes J, Arumugam M, Burgdorf KS, Manichanh C, Nielsen T, Pons N, Levenez F, Yamada T, Mende DR, Li J, Xu J, et al. A human gut microbial gene catalogue established by metagenomic sequencing. Nature. 2010; 464:59-68.

35. Eckburg PB, Bik EM, Bernstein CN, Purdom E, Dethlefsen L, Sargent M, Gill SR, Nelson KE, Relman DA. Diversity of the human intestinal microbial flora. Science. 2005; 308:1635-1638.

36. Cash HL, Whitham CV, Behrendt CL, Hooper LV. Symbiotic bacteria direct expression of an intestinal bactericidal lectin. Science. 2006; 313:1126-1130.

37. Tamboli CP, Neut C, Desreumaux P, Colombel JF. Dysbiosis in inflammatory bowel disease. Gut. 2004; 53:1-4.

38. Anderson JL, Edney RJ, Whelan K. Systematic review: faecal microbiota transplantation in the management of inflammatory bowel disease. Aliment Pharmacol Ther. 2012; 36:503-516.

39. Roediger WE. Utilization of nutrients by isolated epithelial cells of the rat colon. Gastroenterology. 1982; 83:424-429.

40. Kabeerdoss J, Sankaran V, Pugazhendhi S, Ramakrishna BS. Clostridium leptum group bacteria abundance and diversity in the fecal microbiota of patients with inf lammatory bowel disease: a case-control study in India. BMC Gastroenterol. 2013; 13:1-8.

41. Kumari R, Ahuja V, Paul J. Fluctuations in butyrateproducing bacteria in ulcerative colitis patients of North India. World J Gastroenterol. 2013; 19:3404-3414.

42. Wells CL, van de Westerlo EM, Jechorek RP, Feltis BA, Wilkins TD, Erlandsen SL. Bacteroides fragilis enterotoxin modulates epithelial permeability and bacterial internalization by HT-29 enterocytes. Gastroenterology. 1996; 110:1429-1437.

43. Darfeuille-Michaud A, Neut C, Barnich N, Lederman E, Di Martino P, Desreumaux P. Presence of adherent Escherichia coli strains in ileal mucosa of patients with Crohn's disease. Gastroenterology. 1998; 115:1405-1413.

44. Boudeau J, Glasser AL, Masseret E. Invasive ability of an Escherichia coli strain isolated from the ileal mucosa of a patient with Crohn's disease. Infect Immun. 1999; 67:4499-4509.
45. Glasser AL, Boudeau J, Barnich N. Adherent invasive Escherichia coli strains from patients with Crohn's disease survive and replicate within macrophages without inducing host cell death. Infect Immun. 2001; 69:5529-5537.

46. Madsen KL, Doyle JS, Jewell LD, Tavernini MM, Fedoraket RN. Lactobacillus species prevents colitis in interleukin 10 gene-deficient mice. Gastroenterology. 1999; 116:1107-1114.

47. Shibolet O, Karmeli F, Eliakim R, Swennen E, Brigidi P, Gionchetti P, Campieri M, Morgenstern S, Rachmilewitz D. Variable response to probiotics in two models of experimental colitis in rats. Inflamm Bowel Dis. 2002; 8:399-406.

48. Gotteland M, Cruchet S, Verbeke S. Effect of Lactobacillus ingestion on the gastrointestinal mucosal barrier alterations induced by indometacin in humans. Aliment Pharmacol Ther. 2001; 15:11-17.

49. Dieleman LA, Goerres MS, Arends A, Sprengers D, Torrice C, Hoentjen F, Grenther WB, Sartor RB. Lactobacillus GG prevents recurrence of colitis in HLA-B27 transgenic rats after antibiotic treatment. Gut. 2003; 52:370-376.

50. Zackular JP, Rogers MA, Ruffin MT, Schloss PD. The human gut microbiome as a screening tool for colorectal cancer. Cancer Prev Res (Phila). 2014; 7:1112-1121.

51. Alkadhi S, Kunde D, Cheluvappa R, Randall-Demllo S, Eri R. The murine appendiceal microbiome is altered in spontaneous colitis and its pathological progression. Gut Pathog. 2014; 6:25-33.

52. Bitiren M, Karakilcik AZ, Zerin M, Ozardali I, Selek S, Nazligül Y, Ozgonul A, Musa D, Uzunkoy A. Protective effects of selenium, vitamin E combination on experimental colitis in blood plasma and colon of rats. Biol Trace Elem Res. 2010; 136:87-95.

53. Infanteduarte $\mathrm{C}$, Horton $\mathrm{HF}$, Byrne MC, Kamradt $\mathrm{T}$. Microbial lipopeptides induce the production of IL-17 in Th cells. J Immunol. 2000; 165:6107-6115.

54. Scheiffele F, Fuss IJ. Induction of TNBS colitis in mice. Curr Protocols Immunol. 2001; 15:15.19.1-15.19.14.

55. Yang M, Lin HB, Gong S, Chen PY, Geng LL, Zeng YM, Li DY. Effect of Astragalus polysaccharides on expression of TNF-a, IL-1b and NFATc4 in a rat model of experimental colitis. Cytokine. 2014; 70:81-86.

56. Cooper HS, Murthy SN, Shah RS, Sedergran DJ. Clinicopathologic study of dextran sulfate sodium experimental murine colitis. Lab Invest. 1993; 69:49-238.

57. Sun Q, Li A, Li M, Hou B. Effect of $\mathrm{pH}$ on biodiesel production and the microbial structure of glucosefed activated sludge. Int Biodeterior Biodegrad. 2015; 104:224-230.

58. Caporaso JG, Kuczynski J, Stombaugh J, Bittinger K, Bushman FD, Costello EK, Fierer N, Pena AG, Goodrich JK, Gordon JI, Huttley GA, Kelley ST, Knights D, et al. QIIME allows analysis of high-throughput community sequencing data. Nat Methods. 2010; 7:335-336. 
59. Amato KR, Yeoman CJ, Kent A, Righini N, Carbonero F, Estrada A, Gaskins HR, Stumpf RM, Yildirim S, Torralba M, Gillis M, Wilson BA, Nelson KE, et al. Habitat degradation impacts black howler monkey (Alouatta pigra) gastrointestinal microbiomes. ISME J. 2013; 7:1344-1353.

60. Westcott SL, Schloss PD. De novo clustering methods outperform reference-based methods for assigning $16 \mathrm{~S}$ rRNA gene sequences to operational taxonomic units. PeerJ. 2015; 3:1487-1510.

61. Schloss PD, Westcott SL, Ryabin T, Hall JR, Hartmann M, Hollister EB, Lesniewski RA, Oakley BB, Parks DH, Robinson CJ, Sahl JW, Stres B, Thallinger GG, et al.
Introducing mothur: open-source, platform-independent, community-supported software for describing and comparing microbial communities. Appl Environ Microbiol. 2009; 75:7537-7541.

62. Lozupone C, Lladser ME, Knights D, Stombaugh J, Knight R. UniFrac: an effective distance metric for microbial community comparison. ISME J. 2011; 5:169-172.

63. Wu MN, Wu YQ, Deng BG, Li JS, Cao HY, Qu Y, Qian $\mathrm{XL}$, Zhong GS. Isoliquiritigenin decreases the incidence of colitis-associated colorectal cancer by modulating the intestinal microbiota. Oncotarget. 2016; 7: 85318-85331. https://doi.org/10.18632/oncotarget.13347. 